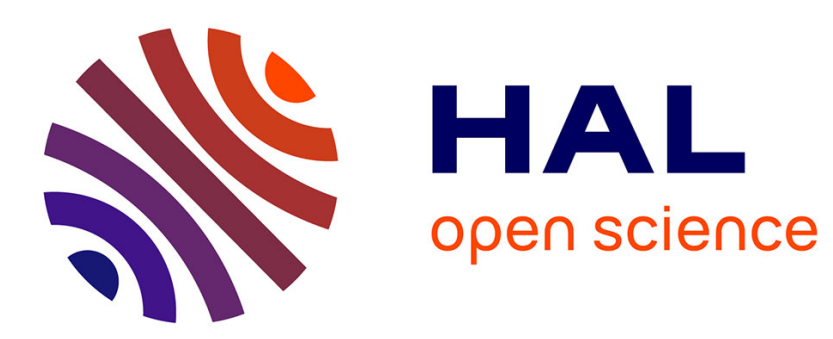

\title{
Identification of the five human species including by real-time polymerase chain reaction
}

\author{
O. Oddoux, A. Debourgogne, A. Kantele, C. H. Kocken, T. S. Jokiranta, S. \\ Vedy, J. M. Puyhardy, M. Machouart
}

\section{- To cite this version:}

O. Oddoux, A. Debourgogne, A. Kantele, C. H. Kocken, T. S. Jokiranta, et al.. Identification of the five human species including by real-time polymerase chain reaction. European Journal of Clinical Microbiology and Infectious Diseases, 2010, 30 (4), pp.597-601. 10.1007/s10096-010-1126-5 . hal00652143

\section{HAL Id: hal-00652143 \\ https://hal.science/hal-00652143}

Submitted on 15 Dec 2011

HAL is a multi-disciplinary open access archive for the deposit and dissemination of scientific research documents, whether they are published or not. The documents may come from teaching and research institutions in France or abroad, or from public or private research centers.
L'archive ouverte pluridisciplinaire $\mathbf{H A L}$, est destinée au dépôt et à la diffusion de documents scientifiques de niveau recherche, publiés ou non, émanant des établissements d'enseignement et de recherche français ou étrangers, des laboratoires publics ou privés. 
Identification of the five human Plasmodium species including $P$. knowlesi by real-time polymerase chain reaction

Oddoux O. ${ }^{1,2,3}$, Debourgogne A., ${ }^{1,2}$, Kantele A. ${ }^{4,5}$, Kocken C. H. ${ }^{6}$, Jokiranta T. S. ${ }^{5}$, Vedy S. ${ }^{3}$, Puyhardy J. M. ${ }^{3}$, Machouart M. ${ }^{1,2 *}$

${ }^{1}$ Service de parasitologie et de mycologie, Hôpitaux de Brabois, CHU de Nancy, 11 allée du Morvan, 54511 Vandoeuvre-les-Nancy, France

${ }^{2}$ Laboratoire de Parasitologie-Mycologie, EA RHEM 4369, Faculté de Médecine, 9 Avenue de la Forêt de Haye, 54500 Vandoeuvre-les-Nancy, France

${ }^{3}$ Service de biologie clinique, Hôpital d'Instruction des Armées Legouest, 27, avenue de Plantières - B.P. 90001, 57077 Metz Cedex 3, France

${ }^{4}$ Division of Infectious Diseases, Department of Medicine, Helsinki University Central Hospital, Helsinki, Finland

${ }^{5}$ Haartman Institute, University of Helsinki, Finland

${ }^{6}$ Department of Parasitology, Biomedical Primate Research Centre, 2280 GH Rijswijk, The Netherlands

* Corresponding author: Dr. Marie Machouart, Service de Parasitologie et de Mycologie, Hôpitaux de Brabois, CHU de Nancy, 11 allée du Morvan, 54511 Vandoeuvre-les-Nancy, France and EA RHEM 4369, Faculté de Médecine, Laboratoire de Parasitologie-Mycologie, 9 Avenue de la Forêt de Haye, 54500 Vandoeuvre-les-Nancy, France. Phone : 00-33-3-83-15-43-97 / fax : 00-33-3-8315-43-86. Mail : $\underline{\text { m.machouart@ chu-nancy.fr }}$ 


\begin{abstract}
(146 words)
Recently, Plasmodium knowlesi has been recognized as the fifth Plasmodium species causing malaria in humans. Hundreds of human cases infected with this originally simian Plasmodiumspecies have been described in Asian countries and increasing numbers are reported in Europe from travellers. The growing impact of tourism and economic development in South and Southeast Asia are expected subsequently to lead to a further increase in cases both among locals and travellers. $P$. knowlesi is easily misidentified in microscopy as $P$. malariae or $P$. falciparum. We developed new primers for the rapid and specific detection of this species by low cost real-time PCR and added this method to an already existing panel of primers used for the molecular identification of the other four species in one reaction. At the moment, reference laboratories should be able to identify undisputably and rapidly P. knowlesi as it is a potentially fatal pathogen.
\end{abstract}

Keywords: P. knowlesi, identification, real-time PCR, diagnosis. 


\section{INTRODUCTION}

Until recently, human malaria was known to be caused only by the four species Plasmodium falciparum, $P$. vivax, $P$. ovale and $P$. malariae. Newly, retrospective studies with molecular tools have also shown hundreds of human cases infected with a simian Plasmodium species, P. knowlesi in numerous Southeast Asian countries, most in Sarawak and Sabah, Malaysian Borneo [1, 2], others in other parts of Borneo [3], in Peninsular Malaysia [4], Thailand [5], Myanmar [6], Philippines [7], Singapore [8] and Vietnam [9, 10]. Concomitantly, increasing numbers have been described in travellers returning from these areas [11-17]. This parasite has been recognized in 2008 by the WHO as the fifth human Plasmodium species potentially leading to fatal outcome [18-20]. The growing impact of tourism and economic development in South and Southeast Asia are expected subsequently to lead to a further increase in cases both among locals and travellers. Therefore, an early and accurate identification of suspected cases is warranted both in order to be able to start immediately the appropriate treatment and to improve the follow-up. Unfortunately, conventional diagnostic techniques such as microscopic analyses of asexual stages of Plasmodium on thick and thin blood films are unable to distinguish early trophozoïtes of $P$. knowlesi from $P$. falciparum and later erythrocytic stages from those of $P$. malariae [21, 22]. Molecular methods have therefore been described to help in detection of this life-threatening species. Babady et al. used a first set of FRET probes in real-time polymerase chain reaction to differentiate the four species $P$. falciparum, P. vivax, P. ovale, P. malariae according to different melting temperatures [23]. Based on this analysis, $P$. knowlesi was indistinguishable from $P$. vivax. Therefore, the authors have designed a second specific set of FRET probes for $P$. knowlesi. This assay allows the detection of the five Plasmodium species in a same run but the two set of probes increase the cost of the reaction. 
We have previously adapted with slight modifications the SYBR Green real-time PCR from de Montbrison et al. in order to identify and differentiate the four Plasmodium species: P. falciparum, $P$. vivax, $P$. ovale and $P$. malariae [24]. In the present study, we have expanded the method to the detection of the fifth human Plasmodium species, P. knowlesi.

\section{MATERIALS AND METHODS}

\section{Bioinformatic study}

In order to add the detection of $P$. knowlesi to the already used assay, a specific primer set was designed. A set of 87 small sub-unit gene sequences corresponding to the five Plasmodium species was recovered from two databases Genbank (NCBI; http://www.ncbi.nlm.nih.gov/pubmed/) and Plasmo DB (Malaria Parasite Genome Project; http://plasmodb.org/). Among them, fifty correspond to P. knowlesi with 37 sequences of A-type and 13 sequences of S-type. Ten sequences correspond to P. falciparum (5 A-type and 5 S-type), 14 to P. vivax (11 A-type and 3 S-type), 8 to P. ovale (7 A-type and 1 unidentified), and 5 to P. malariae (1 A-type and 4 unidentified).

The selected sequences were aligned using the BioEdit Sequence Alignement Editor ${ }^{\circledR}$ (version 7.0.5.3). Regions of conserved alignment for P. knowlesi but with enough polymorphisms with the four other Plasmodium species were then searched for to design of specific $P$. knowlesi primers.

\section{DNA extraction and controls}

Nucleid acids of blood samples were extracted by using the MagNA Pure LC automated system with the MagNA Pure LC Microbiology Kit $\mathrm{M}^{\text {Grade }}$ according to the manufacturer's instructions (Roche Diagnostics, France). Samples were kept at $-80^{\circ} \mathrm{C}$ until used. 
Two P. knowlesi samples taken from European tourists were used control the specificity of the primers $[11,15]$.

A positive control plasmid of $P$. knowlesi was constructed to evaluate the sensitivity of the method. DNA was amplified with the primers PkF1140 5'GATTCATCTATTAAGAATTTGCTTC-3' [25] and PKg'R 5'CAAATCCACTATATTCAATTCTACA-3', framing the specific region PKe'F -PKg'R and the PCR product was cloned into a plasmid (PCR Cloning kit®, Qiagen). Recombinant clones were selected and plasmid DNA was extracted, purified and quantified spectrophotometrically. Ten-fold serial dilutions in sterile water were prepared to obtain concentration from $10^{10}$ plasmid copies / $\mu 1$ to 10 copy / $\mu 1$.

\section{Real-time PCR}

The already used analysis targets the A-type $18 \mathrm{~S}$ ribosomal subunit gene of Plasmodium $\mathrm{sp}$ and is based on the fluorescent SYBR Green I dye used on a LightCycler (Roche Diagnostic, France). In this assay the primers PSP1AS (5'-CTACTCCTATTAATCGTAACT-3'), PFS1 (5'CATTTAAACTGGTTTGGGAAAAC-3') or POS1 (5'-GCATTCCTTATCCAAAATGTG-3') are used in order to detect $P$. falciparum and $P$. ovale, respectively, and the primers PM1 (5'-

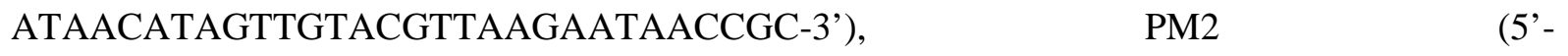
AAAATTCCCATGCATAAAAAATTATACAAA-3'), CGCTTCTAGCTTAATCCACATAACTGATAC-3') and PV2 (5'CTTCCAAGCCGAAGCAAAGAAAGTCCTTA-3') are used to detect $P$. malariae and $P$. vivax [24].

The reaction is performed in a final volume of $20 \mu$, containing five microliters of DNA extracted from blood samples, $5 \mu$ l of LightCycler FastStart DNA Master SYBR Green I Buffer 
(Roche Diagnostics, France), $2.4 \mu \mathrm{l}$ of $\mathrm{MgCl}_{2}(4 \mathrm{mM})$, and $0.6 \mu \mathrm{l}$ of each primer (initial concentration $10 \mu \mathrm{M}$, final concentration $0.3 \mu \mathrm{M})$.

The PCR program is similar for the five Plasmodium species: after an initial denaturation step of 8 minutes at $95^{\circ} \mathrm{C}, 40$ cycles of denaturation at $95^{\circ} \mathrm{C}$ for $10 \mathrm{~s}$., annealing at $58^{\circ} \mathrm{C}$ for $10 \mathrm{~s}$. and extension at $72^{\circ} \mathrm{C}$ for $30 \mathrm{~s}$. are performed. The melting curve is measured after $2 \mathrm{~s}$. denaturation at $95^{\circ} \mathrm{C}$ followed by annealing $\left(20 \mathrm{~s}\right.$. at $\left.50^{\circ} \mathrm{C}\right)$ and slow increase in temperature $\left(0.2^{\circ} \mathrm{C} / \mathrm{s}\right.$. until $98^{\circ} \mathrm{C}$ ) to detect the temperature needed for denaturation.

\section{RESULTS}

After the initial selection of several primer sets, the primers PKe'F (designed at the same location than the antisens primer PkR1150 from Imwong et al. [25]) (5'TCTTTTCTCTCCGGAGATTAGAACTC-3') and PKg'R (5'-CAAATCCACTATATTCAATTCTACA3') targeting the A type of SSU gene were chosen for specific amplification of $P$. knowlesi to obtain a $312 \mathrm{bp}$ amplicon. These new primers were added to the above described protocol.

Results were analyzed with the threshold cycle $(\mathrm{Ct})$, corresponding to the cycle at which the fluorescence signal becomes significantly different from the baseline signal and with the post amplification melting curve analysis that is related to the sequence of the PCR products. The quantity of DNA amplified is not directly equivalent to the parasitaemia present in the original blood sample. Amplifications of each five Plasmodium species with their specific primers result in specific melting temperatures: $78^{\circ} \mathrm{C}$ for $P$. falciparum, $79^{\circ} \mathrm{C}$ for $P$. ovale, $80^{\circ} \mathrm{C}$ for $P$. vivax, $74^{\circ} \mathrm{C}$ for P. malariae and $86^{\circ} \mathrm{C}$ for $P$. knowlesi. For each primer set, nonspecific amplification was excluded by the lack of amplification and melting curve with DNA of the four other species as with noninfected blood samples. The specificity of this assay was tested by using other common blood 
pathogens as Candida albicans, Toxoplasma gondii, Staphylococcus aureus, Pseudomonas aeruginosa, Cytomegalovirus and Hepatitis B virus. All these control pathogens resulted in negative amplification demonstrating the specificity of the primers (Fig 1).

The analytical sensitivity was determined with the concentration of the last positive amplicon obtained with a reliable reproducibility to be $10^{2}$ copies / $\mu$ l (corresponding to a $\mathrm{Ct}=34$ cycles).

\section{DISCUSSION}

As the number of human P. knowlesi cases increases, clinicians and laboratory personnel should be alerted to this emerging - and potentially even lethal - cause of malaria, especially as it is easily misidentified as less dangerous $P$. malariae on microscopy [22]. Until now, the gold standard in malaria diagnosis is indeed based on microscopical examination of blood films but it remains difficult to detect mixed infections, low parasitaemia, atypical forms of Plasmodium sp. potentially modified by treatment as well as this fifth species, P. knowlesi. During last years, conventional methods have been improved by molecular tools. Therefore, laboratories should be able, now, to confirm or exclude the diagnosis of $P$. knowlesi malaria. Due to the uncertainty in identifying this species by microscopic analysis, and the absence of a reliable specific and sensitive rapid diagnostic test, molecular techniques are now the key for achieving this diagnosis.

In this study, we developed a real-time PCR analysis based on SYBR Green in order to identify $P$. knowlesi in addition to the four other human malaria species. Importantly, this technology remains low cost in comparison with the use of FRET probes. The method suits for use both in non-endemic areas such as Europe where only travellers with fever need to be tested and also in endemic areas in Southeast Asia where large-scale testing is required. The numbers of imported cases from travellers are certainly underestimated due to the difficulties in identifying 
exactly the species. Moreover, the areas of potential spread in Southeast and South Asia where the vector mosquito has spread [18] should be explored more thoroughly to get accurate information on the distribution of the disease. Novel accurate tests such as the one presented here are needed as tools for such investigations. They are also needed for diagnostics in the ordinary laboratories investigating patient samples from endemic areas or from travellers returning with fever from such areas.

1453 words.

\section{Acknowledgments}

We are grateful to the staff of the CNR Paludisme (Centre National de Reference du Paludisme, France) for helpful discussions in the fields. 


\section{References}

1. Singh B, Kim Sung L, Matusop A, Radhakrishnan A, Shamsul SS, Cox-Singh J, Thomas A, Conway DJ (2004) A large focus of naturally acquired Plasmodium knowlesi infections in human beings. Lancet 363:1017-24

2. Lee KS, Cox-Singh J, Brooke G, Matusop A, Singh B (2009) Plasmodium knowlesi from archival blood films: further evidence that human infections are widely distributed and not newly emergent in Malaysian Borneo. Int J Parasitol 39(10):1125-8.

3. Sulistyaningsih E, Fitri LE, Loscher T, Berens-Riha N (2010) Diagnostic difficulties with Plasmodium knowlesi infection in humans. Emerg Infect Dis 16:1033-4

4. Cox-Singh J, Davis TM, Lee KS, Shamsul SS, Matusop A, Ratnam S, Rahman HA, Conway DJ, Singh B (2008) Plasmodium knowlesi malaria in humans is widely distributed and potentially life threatening. Clin Infect Dis 46(2):165-71.

5. Putaporntip C, Hongsrimuang T, Seethamchai S, Kobasa T, Limkittikul K, Cui L, Jongwutiwes S (2009) Differential prevalence of Plasmodium infections and cryptic Plasmodium knowlesi malaria in humans in Thailand. J Infect Dis 199:1143-50

6. Jiang N, Chang Q, Sun X, Lu H, Yin J, Zhang Z, Wahlgren M, Chen Q (2010) Co-infections with Plasmodium knowlesi and other malaria parasites, Myanmar. Emerg Infect Dis 16:1476-8

7. Luchavez J, Espino F, Curameng P, Espina R, Bell D, Chiodini P, Nolder D, Sutherland C, Lee KS, Singh B (2008) Human Infections with Plasmodium knowlesi, the Philippines. Emerg Infect Dis $14: 811-3$

8. Ng OT, Ooi EE, Lee CC, Lee PJ, Ng LC, Pei SW, Tu TM, Loh JP, Leo YS (2008) Naturally acquired human Plasmodium knowlesi infection, Singapore. Emerg Infect Dis 14:814-6 
9. Van den Eede P, Van HN, Van Overmeir C, Vythilingam I, Duc TN, Hung le X, Manh HN, Anné J, D'Alessandro U, Erhart A (2009) Human Plasmodium knowlesi infections in young children in central Vietnam. Malar J 8: 249

10. Cox-Singh J (2009) Knowlesi malaria in Vietnam. Malar J 8:269

11. Kantele A, Marti H, Felger I, Müller D, Jokiranta TS (2008) Monkey malaria in a European traveler returning from Malaysia. Emerg Infect Dis 14(9):1434-6

12. Centers for Disease Control and Prevention (CDC) (2008) Simian malaria in a U.S. traveler-New York. MMWR Morb Mortal Wkly Rep 58(9):229-32

13. Bronner U, Divis PC, Färnert A, Singh B (2009) Swedish traveller with Plasmodium knowlesi malaria after visiting Malaysian Borneo. Malar J 8:15

14. Anonymous (2010) Imported malaria cases and deaths, United Kingdom: 1990 - 2009: Health Protection Agency:Electronic publication.

http://www.hpa.org.uk/Topics/InfectiousDiseases/InfectionsAZ/Malaria/Epidemi

15. van Hellemond JJ, Rutten M, Koelewijn R, Zeeman AM, Verweij JJ, Wismans PJ, Kocken CH, van Genderen PJ (2009) Human Plasmodium knowlesi infection detected by rapid diagnostic tests for malaria. Emerg Infect Dis 15(9):1478-80.

16. Ta TT, Salas A, Ali-Tammam M, Martínez Mdel C, Lanza M, Arroyo E, Rubio JM (2010) First case of detection of Plasmodium knowlesi in Spain by Real Time PCR in a traveller from Southeast Asia. Malar J 9:219.

17. Figtree M, Lee R, Bain L, Kennedy T, Mackertich S, Urban M, Cheng Q, Hudson BJ (2010) Plasmodium knowlesi in human, Indonesian Borneo. Emerg Infect Dis 16(4):672-4. 
18. Cox-Singh J, Singh B (2008) Knowlesi malaria: newly emergent and of public health importance? Trends Parasitol 24(9):406-10

19. White NJ. (2008) Plasmodium knowlesi: the fifth human malaria parasite. Clin Infect Dis 46(2):172-3.

20. Cox-Singh J, Hiu J, Lucas SB, Divis PC, Zulkarnaen M, Chandran P, Wong KT, Adem P, Zaki SR, Singh B, Krishna S (2010) Severe malaria - a case of fatal Plasmodium knowlesi infection with post-mortem findings: a case report. Malar J 9:10.

21. Sulistyaningsih E, Fitri LE, Löscher T, Berens-Riha N (2010) Diagnostic difficulties with Plasmodium knowlesi infection in humans. Emerg Infect Dis 16(6):1033-4

22. Daneshvar C, Davis TM, Cox-Singh J, Rafa'ee MZ, Zakaria SK, Divis PC, Singh B (2009) Clinical and laboratory features of human Plasmodium knowlesi infection. Clin Infect Dis 49(6):852-60.

23. Babady NE, Sloan LM, Rosenblatt JE, Pritt BS (2009) Detection of Plasmodium knowlesi by real-time polymerase chain reaction. Am J Trop Med Hyg 81(3):516-8.

24. de Monbrison F, Angei C, Staal A, Kaiser K, Picot S (2003) Simultaneous identification of the four human Plasmodium species and quantification of Plasmodium DNA load in human blood by real-time polymerase chain reaction. Trans R Soc Trop Med Hyg 97(4):387-90

25. Imwong M, Tanomsing N, Pukrittayakamee S, Day NP, White NJ, Snounou G (2009) Spurious amplification of a Plasmodium vivax small-subunit RNA gene by use of primers currently used to detect P. knowlesi. J Clin Microbiol 47(12):4173-5 
Figure Legend

Figure 1. Specific detection of Plasmodium knowlesi with the primers PKe'F and PKg'R in SYBR Green real-time PCR.

A. Amplification curve of P. knowlesi. Samples containing DNA from P. falciparum, P. vivax, $P$. ovale and $P$. malariae did not result in amplification of DNA with the primers PKe'F and PKg'R.

B. Melting curves analysis. The melting temperature obtained with $P$. knowlesi specific primers PKe' $\mathrm{F}$ and $\mathrm{PKg}$ 'R is $86^{\circ} \mathrm{C}\left(+/-0.5^{\circ} \mathrm{C}\right)$. No curve was obtained using the same primers with the other human Plasmodium species. 